\title{
Selective Amplification of DNA Fragments Coding for the G Domain of Factors IF2 and EF-Tu, Two G Proteins from the Myxobacterium Stigmatella aurantiaca
}

\author{
L. Bremaud, B. Derijard, ${ }^{1}$ and Y. Cenatiempo
}

Institut de Biologie Moléculaire et d'Ingénierie Génétique, Centre National de la Recherche Scientifique (CNRS) URA1172,

Université de Poitiers, 86022 Poitiers Cedex, France

Two DNA fragments of the genome of the myxobacterium stigmatella aurantiaca were selectively amplified by PCR. These fragments encode a segment of the $G$ domain of translational initiation factor IF2 and elongation factor EF-Tu, two GTP-binding proteins. This was made possible by carefully designing the primers for this reaction to avoid the amplification of every G-domain-encoding region of the genome. The sequence of two pairs of primers was deduced from highly conserved regions, namely $G_{1}$ and $G_{3}$ and/or their vicinal amino acids, within each subfamily (initiation and elongation factors, respectively) of GTP-binding proteins. On the basis of the expected size, one band was selected in each experiment, cloned into a vector, and sequenced. This showed unambiguously after comparison analysis that they belong to the IF2 and EF-Tu genes, respectively. This strategy seems suitable for the amplification of a segment of any gene coding for a $G$ protein from any origin.
'Present address: Howard Hughes Medical Institute Research Laboratories, University of Massachusetts Medical Center, II Biotech Park, Worcester, Massachusetts 01605 USÁ.
$S$ elective amplification of DNA fragments is desired as the first step in gene cloning experiments, especially when the use of homologous probe is required. This situation occurs when dealing with a family of proteins with members that display strong similarities in their primary structure. In this respect, an interesting example is provided by the widely spread GTP-binding proteins (G proteins).

The members of the $G$ protein superfamily $^{(1)}$ are involved in diverse biological processes such as transmembrane signaling, control of proliferation and differentiation, and initiation and elongation of protein synthesis in prokaryotes and eukaryotes. ${ }^{(2-5)}$ In spite of these different roles, similar molecular mechanisms occur for GTP binding (active form) followed by its hydrolysis into GDP (inactive form). Conserved primary and presumably tertiary protein structures were identified, especially within the $\mathrm{G}$ domain bearing the most conserved motifs. ${ }^{(1,6)}$

It is now accepted that at least four conserved regions, termed $G_{1}$ to $G_{4}$, are found throughout all the superfamily, but with an even higher homology within subgroups such as translational initiation factors, elongation factors, small eukaryotic GTPases like Ras proteins, and subunits of signal-transducing $\mathrm{G}$ proteins. Consensus sequence motifs have been proposed: GXXXXGKS/T, D-Xn-T, DXXG, and NKXD within $G_{1}$, $G_{2}, G_{3}$, and $G_{4}$, respectively. ${ }^{(1)}$

We began studying GTP-binding proteins in Stigmatella aurantiaca, a myxo- bacterial species, because under starvation these prokaryotic cells undergo a developmental cycle leading to the formation of particular structures termed fruiting bodies. ${ }^{(7,8)}$ Multicellular development of myxobacteria is sustained by signal exchanges presumably transduced by $G$ proteins, as in most eukaryotes. ${ }^{(9,10)}$ Two soluble $G$ proteins, translational initiation IF2 and elongation factor EF-Tu, may also play a role, directly or indirectly, in this developmental process, via the selection and translation of particular mRNAs.

IF2 and EF-Tu are present in different forms in bacteria, and they arise from different processes. In Escherichia coli, one gene, infB, directs the synthesis of the various forms of IF2, caused by the presence of several translational initiation sites on infB mRNA, ${ }^{(11)}$ whereas EF$\mathrm{Tu}$ appears as two polypeptides bearing a different amino acid at the carboxyl terminus. The latter are coded by two genes, tufA and tufB, differing only in 13 positions out of a total of 1185 nucleotides; 8 of the 13 positions are located within the region encoding the $G$ domain. ${ }^{(12,13)}$

In this report we show that it is possible to amplify specifically a segment of the genes for IF2 and for EF-Tu. This was performed by designing different pairs of primers, taking into account the most conserved sequences, but also the main differences among subfamilies, within and at the border of the consensus regions $G_{1}$ and $G_{3}$.

The amplified DNA fragments, which were identified unambiguously by se- 
quencing, will now be used as homologous probes to clone the corresponding genes of $S$. aurantiaca.

\section{MATERIALS AND METHODS}

\section{Bacterial Strains and Growth Conditions}

S. aurantiaca DW4 was obtained from D. White (Indiana University, Bloomington). This strain was grown at $30^{\circ} \mathrm{C}$ in $1 \%$ Bactocasitone (Difco), with $8 \mathrm{~mm}$ $\mathrm{MgSO}_{4}$, and harvested at $\sim 4.10^{8}$ cells/ ml. E. coli TG1 was grown at $37^{\circ} \mathrm{C}$ in $2 \times$ YT medium. ${ }^{(14)}$

\section{DNA Preparation}

Genomic DNA of $S$. aurantiaca DW4 was extracted by the procedure described by Starich and Zissler. ${ }^{(15)}$

\section{Primer Synthesis}

Degenerate oligonucleotides used for PCR were produced by the phosphoramidite method as described previously, ${ }^{(16)}$ using a Gene Assembler Synthesizer (Pharmacia LKB). Upstream and downstream primers, respectively, were appended with EcoRI and BamHI restriction sites at their $5^{\prime}$ terminus.

\section{PCR Amplification}

PCR was performed with a Gene ATAQ Pharmacia Thermocycler. Amplification of the desired segments was performed in a $50-\mu l$ reaction mixture containing 1 $\mu \mathrm{g}$ of $S$. aurantiaca genomic DNA; 50 pmoles of each primer; $200 \mu \mathrm{M}$ each of dATP, dTTP, dCTP, and dGTP; Taq DNA polymerase buffer $[10 \mathrm{~mm}$ Tris- $\mathrm{HCl}(\mathrm{pH}$ 9), $50 \mathrm{mM} \mathrm{KCl}, 1.5 \mathrm{mM} \mathrm{MgCl}_{2}, 0.1 \%$ Triton X-100; and 1.25 units of Taq DNA polymerase.

Phenol-extracted $S$. aurantiaca genomic DNA was denatured for $5 \mathrm{~min}$ at $100^{\circ} \mathrm{C}$ in the presence of both primers, overlaid with $50 \mu \mathrm{l}$ of mineral oil (Sigma), and then cooled rapidly on ice. Next, dNTPs, Taq DNA polymerase buffer, water, and Taq DNA polymerase were added to the mineral oil and dropped by a brief centrifugation.

Amplification with IF2 primers (infB $G_{1}$ and $G_{3 a}$ ) was carried out as follows: Each cycle consisted of denaturation at $94^{\circ} \mathrm{C}$ for $30 \mathrm{sec}$, annealing at $65^{\circ} \mathrm{C}$ for 30 sec, and extension at $72^{\circ} \mathrm{C}$ for $1 \mathrm{~min}$. This cycle was repeated 30 times. Ampli-

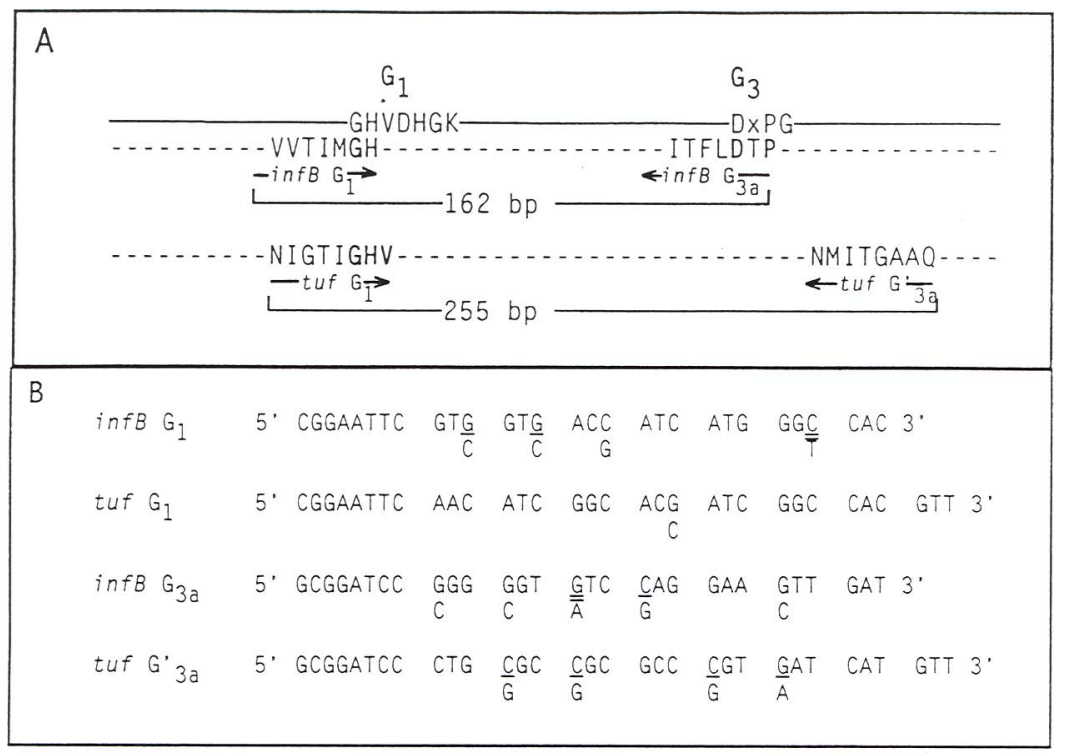

FICURE 1 Conserved amino acid sequences in the G domain of IF2 and EF-Tu $(A)$ and nucleotide sequence of primers used in PCR $(B) .(A) G_{1}$ and $G_{3}$ represent two consensus motifs found throughout $G$ proteins; broken lines correspond to IF2 and EF-Tu, respectively. Only those amino acids taken into account to design the primers (infB $\mathrm{G}_{1}$, infB $\mathrm{G}_{3}$, tuf $\mathrm{G}_{1}$, and tuf $\mathrm{G}_{3 \mathrm{a}}$ ) are displayed. The size (in bp) of the expected PCR fragments is also indicated. $(B)$ The nucleotide sequence of degenerate primers is described. At degenerated positions, in the absence of any other indication, each base represents $50 \%$ of the mixture, whereas underlined or doubly underlined bases represent $66.6 \%$ and $83.3 \%$, respectively, of the mixture. fication with $\mathrm{Tu}$ primers (tuf $\mathrm{G}_{1}$ and $\mathrm{G}^{\prime}{ }_{3 \mathrm{a}}$ ) was almost identical, except that the annealing temperature was dropped to $56^{\circ} \mathrm{C}$.

Twenty microliters of each reaction mixture was loaded onto a $2 \%$ agarose gel. After electrophoresis, amplification products were visualized by ethidium bromide staining. PCR products were purified using the freeze-squeeze method. ${ }^{(17)}$ After extraction and ethanol precipitation, amplification products were digested with BamHI (BRL) and EcoRI (BRL). DNA fragments were subcloned into M13mp19, digested previously with the same restriction enzymes, and transformed into $E$. coli TG1. The single-stranded template was sequenced by the dideoxy chain termination method, ${ }^{(18)}$ using a fluorescent universal M13 primer and T7 DNA polymerase. Sequencing was performed with an automated sequencer (A.L.F., Pharmacia).

\section{Computer Analysis of DNA Sequences}

Computer analysis of PCR fragments was performed using DNAsis software (Hitachi).

\section{RESULTS}

\section{Primer Design}

The first stage of this work was to design two sets of primers to amplify specifically a segment of the genes infB and tuf of $S$. aurantiaca coding for two GTPbinding proteins, repectively, IF2 and EF-Tu. As shown in Figure $1 \mathrm{~A}$, to obtain an amplification of a G-protein-encoding gene segment, we took advantage of (1) conserved amino acid sequences $G_{1}$ and $G_{3}$ to design the primers inf $B G_{1}$, inf $B G_{3 a}$, and tuf $G_{1}$, which overlap those consensus sequences and upstream amino acids; and (2) a conserved stretch of 8 amino acids, located downstream from $G_{3}$, in the $T u$ subgroup of the G-protein family to design tuf $\mathrm{G}^{\prime}{ }_{3 \mathrm{a}}$.

We had to take into account the GC content $(\sim 70 \%)$ of the myxobacterial genome, especially at the third position of codons where it can be as high as $90 \% .{ }^{(19)}$ Moreover, the high GC content of the primers could theoretically lead to secondary structures, because of self-annealing, and to primer-dimer formation. This was estimated by using the OLIGOTEST version 2.0 software, ${ }^{(20)}$ 


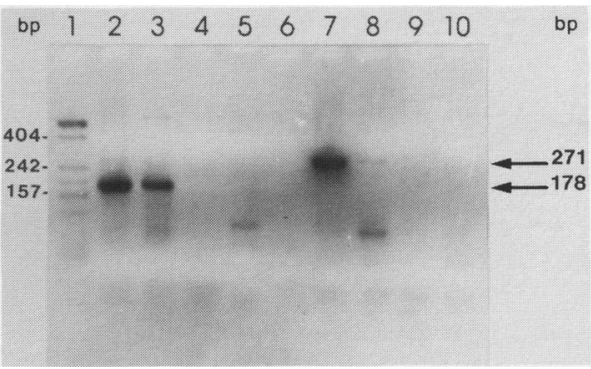

FIGURE 2 Agarose gel analysis of the PCR-amplified products. (Left) The size of relevant markers separated in lane 1 (pBluescript restricted with HpalI); (lanes 2,3) amplification with $\operatorname{infB} \mathrm{G}_{1}$ and infB $\mathrm{G}_{3 \mathrm{a}}$ from $E$. coli and $S$. aurantiaca genomic DNA, respectively; (lanes 4-6) control experiments with inf $B G_{1}$ alone, infB $\mathrm{G}_{3 \mathrm{a}}$ alone, and without DNA, respectively; (lanes 7,8) amplification similar to lanes 2 and 3 but with tuf $G_{1}$ and tuf $G_{3 a}^{\prime}$; (lanes 9,10 ) controls with tuf $\mathrm{G}_{1}$ alone and tuf $\mathrm{G}^{\prime}{ }_{3 \mathrm{a}}$, respectively. (Right) The positions of the expected bands are indicated by arrows and their theoretical sizes are shown.

which indicated that self complementarity within the primers did not exceed 5 bp but that contiguous and noncontiguous complementarity could occur between mainly tuf $G_{1}$ and tuf $G_{3 a}^{\prime}$, thus leading to primer-dimer formation in PCR. Finally, directional cloning in a sequencing vector was done by adding bases at the $5^{\prime}$ terminus of the primers (restriction sites).

Figure 1B shows the sequence of the degenerate primers that were synthesized following the designed specifications. As indicated, only a few positions were degenerated on the basis of codon bias determined from the analysis of 18 sequenced genes of another myxobacterium, Myxococcus xanthus (B. Dérijard, unpubl.). This bacterial species was chosen because insufficient data were available to define codon preferences in the genome of $S$. aurantiaca.

\section{Amplification}

PCR experiments were performed with the two pairs of primers, infB $G_{1} /$ inf $B$ $\mathrm{G}_{3 a}$, and tuf $\mathrm{G}_{1} /$ tuf $\mathrm{G}^{\prime}{ }_{3 a}$, and included negative and positive controls as displayed in Figure 2. Positive controls were carried out by using $E$. coli genomic DNA, the IF2 and EF-TU G domains of which were already described. ${ }^{(2,21,22)}$ The first set of primers, infB $G_{1}$ and $G_{3 a}$, was used to amplify a segment of infB, the IF2 gene. A major amplified product of the same size was obtained with $E$. coli and $S$. aurantiaca DNA (lanes 2 and 3). Two weaker bands of a smaller size were observed with the latter. The lower of these two bands may correspond to an amplification product arising from infB $G_{3 a}$ alone (lane 5), whereas the origin of the other one remains unexplained. The expected size of the major band was 178 bp (162 bp plus $16 \mathrm{bp}$ attributable to the appended EcoRI and BamHI sites). This length is compatible with its observed size (180-200 bp).

In the case of the second set of primers, a unique band seems to correspond to an amplified segment of the $E$. coli EF-Tu gene (tufA or tufB, lane 7), whereas the corresponding band amplified from the genome of $S$. aurantiaca appears weaker than a shorter one, presumably a primer-dimer or a nonspecific amplified product (lane 8). However, we did not try to optimize further the PCR, as the upper band migrates at the expected level $(\sim 270 \mathrm{bp})$ and the estimated amount of DNA was sufficient for subsequent cloning.

\section{Identification of PCR Fragments}

The putative infB and tuf segments of $S$. aurantiaca were inserted into $\mathrm{M} 13 \mathrm{mp} 19$ before sequencing. A comparison of the DNA sequence of these PCR fragments (excluding the above described appended restriction sites) with their $E$. coli counterpart is presented in Figure 3 . The size of the corresponding fragments is absolutely identical in both bacterial species. A $71.5 \%$ identity was calculated between $E$. coli and $S$. aurantiaca 162-bp fragments (Fig. 3, bottom), leading to a $81.5 \%$ amino acid identity (Fig. 4 , bottom). Therefore, one can conclude that the $S$. aurantiaca fragment has been amplified from the infB gene. The situation may be more complex with the 255-bp fragment, as two genes for EF-Tu may be present within the genome of $S$. aurantiaca. However, there is little doubt about the nature of this fragment, which seems to belong to a tuf gene. When compared with the E. coli tufB sequence (Fig. 3, top), the percentage of identity reaches $69.4 \%$ ( $76.5 \%$ for the deduced protein sequence; Fig. 4, top). Whether the se-

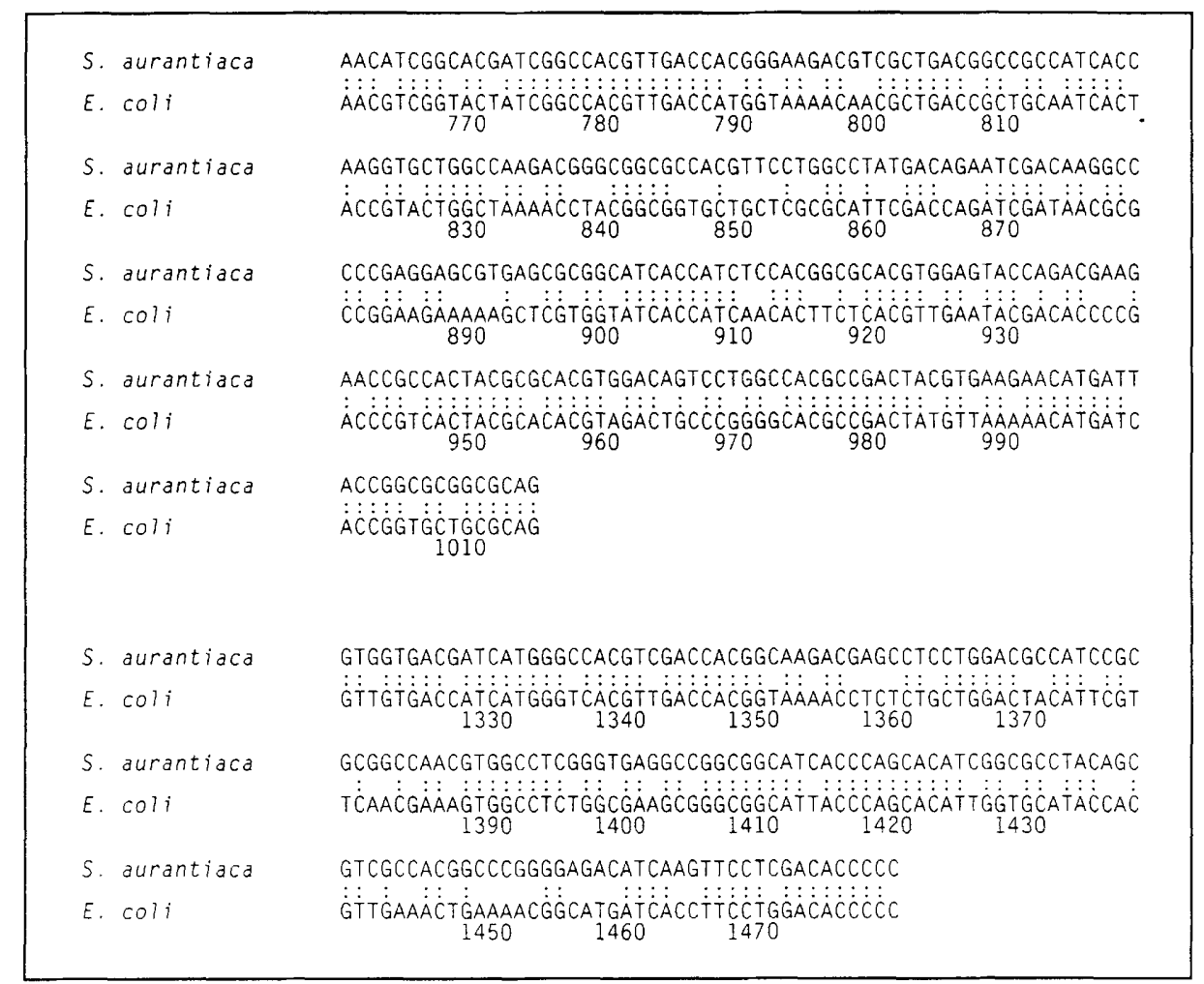

FIGURE 3 Nucleotide sequence of the PCR fragments from $S$. aurantiaca and their alignment with E. coli tufB (top) and infB (bottom) regions coding for part of the G domain of EF-Tu and IF2, respectively. The nucleotide sequence of the restriction sites added to the 5 ' end of the primers is not displayed (see text and Fig. 1). Identical bases are indicated by colons. 


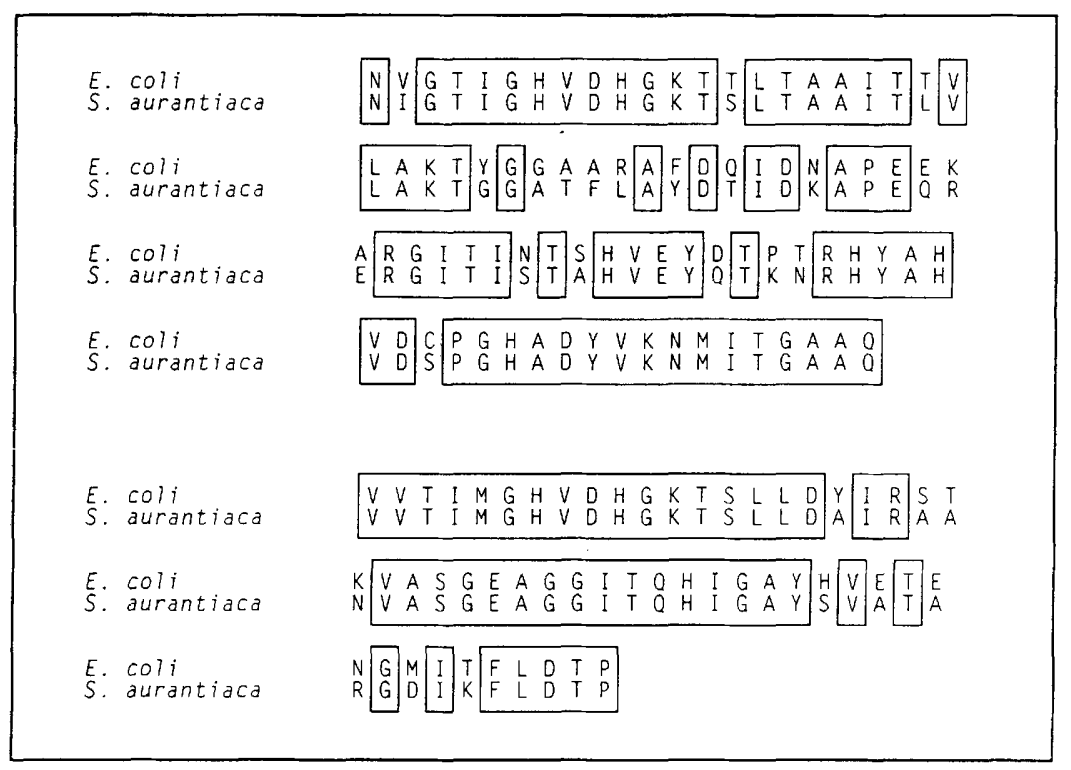

FIGURE 4 Amino acid sequence of $S$. aurantiaca gene products deduced from Fig. 3 aligned with a segment of EF-TU (top) and IF2 (bottom). Conserved sequences are boxed.

quenced fragment represents the equivalent of tufA or tufB gene cannot be assessed from this simple alignment (see Discussion).

\section{DISCUSSION}

The goal of this work was to define a simple strategy to obtain a homologous probe to increase the probability of cloning some, but not all, genes coding for $G$ proteins in a myxobacterial species, $S$. aurantiaca. We thought that the choice of primers based on consensus sequences within the $G$ domain but limited to subfamily homologies was critical. Furthermore, we expected the main problem to be the nature of the myxobacterial genome, namely its high GC content. According to the nucleotide sequence of the amplified products, the strategy appears to be successful in the two chosen cases (infB and tuf segments), in spite of the fact that the amplification was obscured in the second example, probably by primer-dimer formation.

Although these segments represent relatively short portions of the genes, interesting information can already be deduced from their nucleotide sequences. The calculated GC percent in the in $B$ sequence, including the primers, reaches $75 \%$, a value higher than that observed in the $t u f$ sequence, $\sim 65 \%$. More impressive is this percentage at the third codon position, 96\% (infB) and 92\% (tuf). This establishes that we are dealing with a DNA amplified from myxobacteria and rules out any possibility of amplification from contaminating DNA, especially $E$. coli.

Finally, we compared these new sequences with homologous regions in the genome of $E$. coli and other microorganisms. Four infB sequences have already been published, out of which only one is from Gram-negative bacteria $(E \text {. coli })^{(21)}$ and three from gram-positive ones $(\mathrm{Ba}$ cillus subtilis, Streptococcus thermophilus, and Streptococcus faecium). ${ }^{(23-25)}$ It is interesting, knowing that myxobacteria are Gram-negative bacteria, that the homology found with the corresponding sequences is the highest with the $E$. coli genome $(71.5 \%)$. Lower percentages are obtained with the above mentioned Gram-positive bacteria $(66.5 \%, 68 \%$, and $60 \%$, respectively). Such values extended to the overall gene will be important in terms of evolutionary studies.

The presence of two tuf genes in $E$. coli $^{(12,13)}$, or even three in Streptomyces ramocissimus (L.P. Woudt, K. Rietveld, M. Verdurmen, J. Van Haarlem, G.P. Van Wezel, E. Vijgenboom, and L. Basch, unpubl.), raises the question of whether such a situation occurs in $S$. aurantiaca and, consequently, which fragment has been amplified in our experiments. We examined the sequence, especially at those positions where differences be- tween tuf genes have been described in $E$. coli, and were not able to come to a conclusion because three types of situations were encountered: At some positions a nucleotide is identical to that present in tufA (such as a $\mathrm{C}$ at nucleotide 789 ), or in $t u f B$ (such as a $C$ at nucleotide 800 ), or even absent in both genes (such as a $G$ at nucleotide 798 ). Therefore, the sequence of the entire gene as well as the surrounding region of the $S$. aurantiaca genome is required to solve this problem, because tufA is part of a complex operon including a gene (fus $A$ ) coding for the EF-G, another $G$ protein, whereas tufB is preceded by tRNA genes. ${ }^{(12,13)}$

Finally, an analysis of the deduced protein sequences shows a very high degree of conservation within their $G$ domains and confirms that a choice of primers designed only from consensus sequences such as $G_{1}$ or $G_{3}$ could have led to the simultaneous amplification of at least two G-domain-encoding regions. For instance, a long stretch of identical amino acids is found within and after $G_{1}$ of IF2 and EF-Tu of $S$. aurantiaca.

Either amplified fragments or oligonucleotides generated from the most diverged regions within the sequenced segments could be used to clone individual genes. We chose the amplified fragments as homologous probes to screen a $\lambda$ gt11 library of $S$. aurantiaca DW4/3.1 genomic DNA (kindly provided by H.U. Schairer, Zentrum für Molekular Biologie, University of Heidelberg, Germany). On the basis of preliminary sequence data, we have identified clones bearing in $B$ and $t u f B$, respectively (L. Bermaud, B. Dérijard, and Y. Cenatíempo, in prep.).

The strategy proposed here may be extended to other sets of primers and eventually different prokaryotic or eukaryotic organisms. This would allow for the cloning of any gene coding for a member of the very important superfamily of $\mathrm{G}$ proteins.

\section{ACKNOWLEDGMENTS}

We are grateful to Didier Delourme for his help in the preparation of this manuscript.

\section{NOTE ADDED IN PROOF}

The nucleotide sequence data reported in this paper will appear in the EMBL, GenBank, and DDBJ nucleotide sequence data bases under the accession 
numbers $X 75300$ and $X 75301$ for tufB and inf $B$, respectively.

\section{REFERENCES}

1. Bourne, H.R., D.A. Sanders, and F. McCormick. 1991. The GTPase superfamily: Conserved structure and molecular mechanism. Nature 349: 117-127.

2. Cenatiempo, Y., F. Deville, J. Dondon, M. Grunberg-Manago, C. Sacerdot, J.W.B. Hershey, H.F Hansen, H.U. Petersen, B.F.C. Clark, M. Kjieldgaard, T.F.M. La Cour, K.K. Mortensen, and J. Nyborg. 1987. The protein synthesis initiation factor 2 G-domain. Study of a functionally active C-terminal 65-kilodalton fragment of IF2 from Escherichia coli. Biochemistry 26: $5070-5076$.

3. Pfeuffer, T. and E.J.M. Helmreich. 1988. Structural and functional relationships of guanosine triphosphate binding proteins. Curr. Topics Cell Regul. 29: 129-216.

4. Bourne, H.R., D.A. Sanders, and F. McCormick. 1990. The GTPase superfamily: A conserved switch for diverse cell functions. Nature 348: 125-132.

5. Gibbs, J.B. and M.S. Marshall. 1989. The ras oncogene-An important regulatory element in lower eucaryotic organisms. Microbiol. Rev. 53: 171-185.

6. Dever, T.E., M.J. Glynias, and W.C. Merrick. 1987. GTP binding domain: Three consensus elements with distinct spacing. Proc. Natl. Acad. Sci. 84: 1814-1818.

7. Wireman, J.W. and M. Dworkin. 1975. Morphogenesis and developmental interactions in myxobacteria. Science 189: 516-522.

8. Shimkets, L.J. 1990. Social and developmental biology of the myxobacteria. Microbiol. Rev. 54: 473-501.

9. Dérijard, B., M. Ben Aïssa, B. Lubochinsky, and Y. Cenatiempo. 1989. Evidence for a membrane-associated GTP-binding protein in Stigmatella aurantiaca, a prokaryotic cell. Biochem. Biophys. Res. Commun. 158: 562-568.

10. March, P.E. 1992. Membrane-associated GTPases in bacteria. Mol. Microbiol. 6: 1253-1257.

11. Sacerdot, C., G. Vachon, S. Laalami, F. Morel-Deville, Y. Cenatiempo, and $\mathrm{M}$. Grunberg-Manago. 1992. Both forms of translational initiation factor IF2 ( $\alpha$ and $\beta)$ are required for maximal growth of $E s$ cherichia coli. Evidence for two translational initiation codons for IF2 $\beta$. $J$. Mol. Biol. 225: 67-80.

12. Yokota, T., H. Sugisaki, M. Takanami, and Y. Kaziro. 1980. The nucleotide sequence of the cloned tufA gene of Escherichia coli. Gene 12: 25-31.

13. An, G. and J.D. Friesen. 1980. The nucleotide sequence of tufB and four nearby tRNA structural genes of Escherichia coli. Gene 12: 33-39.
14. Davis, L.G., M.D. Dibner, and J.F. Battey, eds. 1986. Basic methods in molecular biology. Elsevier, Amsterdam, The Netherlands.

15. Starich, T. and J. Zissler. 1989. Movement of multiple DNA units between Myxococcus xanthus cells. J. Bacteriol. 171: 23232336.

16. Hartmann, R.K., N. Ulbrich, and V.A. Erdmann. 1987. An unusual rRNA operon constellation: In Thermus thermophilus HB8 the 23S/5S rRNA operon is a separate entity from the 16S rRNA operon. Biochimie 69: 1097-1104.

17. Tautz, D and M. Renz. 1983. An optimized freeze-squeeze method for the recovery of DNA fragments from agarose gels. Anal. Biochem. 132: 14-19.

18. Sanger, F., S. Nicklen, and A.R. Coulson. 1977. DNA sequencing with chain termination inhibitors. Proc. Natl. Acad. Sci. 74: 5463-5467.

19. Mesbah, M., U. Premachandran, and W.B. Whitman. 1989. Precise measurement of the $\mathrm{G}+\mathrm{C}$ content of deoxyribonucleic acid by high-performance liquid chromatography. Int. J. Syst. Bacteriol. 39: 159167.

20. Beroud, C., C. Antignac, C. Jeanpierre, and C. Junien. 1990. Un programme informatique pour la recherche d'amorces pour l'amplification par PCR. Médecinel Sciences 9: 901-903.

21. Sacerdot, C., P. Dessen, J.W.B. Hershey, J. Plumbridge, and M. Grunberg-Manago. 1984. Sequence of initiation factor IF2 gene: Unusual protein features and homologies with elongation factors. Proc. Natl. Acad. Sci. 81: 7787-7791.

22. Laalami, S., C. Sacerdot, G. Vachon, K. Mortensen, H.U. Sperling-Petersen, Y. Cenatiempo, and M. Grunberg-Manago. 1991. Structural and functional domains of $E$. coli initiation factor IF2. Biochimie 73: $1557-1566$.

23. Brombach, M., C.O. Gualerzi, Y. Nakamura, and C.L. Pon. 1986. Molecular cloning and sequence of the Bacillus stearothermophilus translational initiation factor IF2 gene. Mol. Gen. Genet. 205: 97102.

24. Friedrich, K., M. Brombach, and C.L. Pon. 1988. Identification, cloning and sequence of the Streptococcus faecium infB (translational initiation factor IF2) gene. Mol. Gen. Genet. 214: 595-600.

25. Shazand, K., J. Tucker, R. Chiang, K. Stansmore, H.U. Sperling-Petersen, M. Grunberg-Manago, J.C. Rabinowitz, and T. Leighton. 1990. Isolation and molecular genetic characterization of the Bacillus subtilis gene (infB) encoding protein synthesis initiation factor $2 . J$. Bacteriol. 172: $2675-2687$.

Received August 23, 1993; accepted in revised form October 14, 1993. 


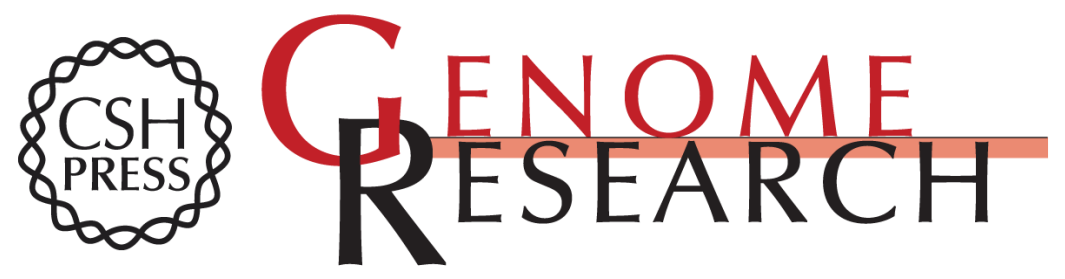

\section{Selective amplification of DNA fragments coding for the G domain of factors IF2 and EF-Tu, two G proteins from the myxobacterium Stigmatella aurantiaca.}

L Bremaud, B Derijard and Y Cenatiempo

Genome Res. 1993 3: 195-199

References This article cites 24 articles, 8 of which can be accessed free at:

http://genome.cshlp.org/content/3/3/195.full.html\#ref-list-1

License

Email Alerting Receive free email alerts when new articles cite this article - sign up in the box at the Service top right corner of the article or click here.

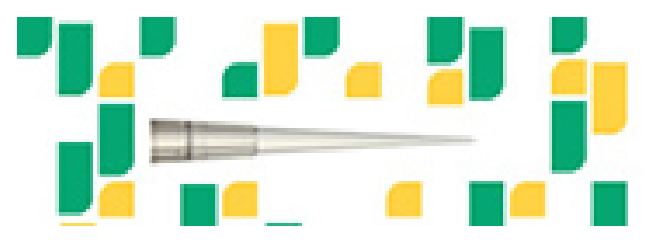

Focused on your science.

To subscribe to Genome Research go to:

https://genome.cshlp.org/subscriptions 